\title{
Pontine metastasis with dissociated bilateral horizontal gaze paralysis
}

\author{
C PIERROT-DESEILLIGNY,* J GOASGUEN, † F CHAIN, ${ }^{*}$ J LAPRESLE $\ddagger$
}

From the Unité de Recherches INSERM U.84, Hôpital de la Salpêtrière, ${ }^{*}$ Paris, the Clinique de Neurologie, Hôpital d'Instruction des Armées du Val-de-Grâce, $\dagger$ Paris, and the Laboratoire de Neuropathologie, Centre Hospitalier de Bicêtre, Kremlin-Bicêtre, $\ddagger$ France

SUMMARY A clinicopathological case of pontine metastatic tumour is reported with an oculomotor syndrome including bilateral horizontal gaze paralysis affecting saccades and foveal pursuit. During full-field pursuit, oculocephalic movement, and after caloric stimulation, the right eye alone was able to move slowly only $30^{\circ}$ to the right of the midline. Convergence and vertical eye movements were unaffected in either eye. The lesion lay in the whole left pontine tegmentum and partly in the right pontine tegmentum which was also strongly compressed and displaced to the right. The bilateral horizontal gaze paralysis resulted from damage to both paramedian pontine reticular formations. The unusual combination of an absence of foveal pursuit with the persistence of a rightward full-field pursuit analysed in the light of recent experimental work, suggested a clear separation between the brainstem pathways of these two types of pursuit movement. Lastly, according to our data and other clinicopathological findings previously reported, it appeared also that the paramedian pontine reticular formation role in the triggering of voluntary vertical saccades is less significant in man than in the monkey.

Numerous experimental and clinical studies have shown that each of the paramedian pontine reticular formations, located near the abducens nuclei (VI), is the last supranuclear relay involved in the generation of all types of ipsilateral horizontal saccades. ${ }^{12}$ The mesencephalic reticular formations, lying just above the oculomotor nuclei (III), have an analogous function in vertical saccades mediation. ${ }^{34}$ For reflex eye movements the immediate premotor relays are the vestibular nuclei. ${ }^{5}$ These nuclei are directly connected to the nuclei of the sixth and third nerves by tracts independent of the reticular formation. Thus, the entrances of the final common pathways for lateral and vertical eye movements are located in the nuclei of the sixth and third nerves respectively. In spite of these advances in our knowledge of ocular motility organisation, it remains uncertain which pathways are involved in the different pursuit movements, and what is the functional influence of the paramedian pontine reticular forma-

Address for reprint requests: Dr Ch. Pierrot-Deseilligny, Hôpital de la Salpêtrière, 47 Bld de rHôpital, 75634 Paris - Cedex 13, France.

Received 16 May 1983 and in revised form 29 August 1983. Accepted 12 September 1983 tion on the mesencephalic reticular formation. The clinicopathological findings reported here provide new information about these two questions.

\section{Case report}

A 59-year-old man was admitted to hospital on 19 July 1979 for a progressive right hemiparesis which had arisen two weeks previously. A CT scan showed a left frontoparietal tumoral lesion. At operation on 30 July an epithelioma metastasis was removed. The primary tumour was a bronchogenic carcinoma discovered a few months later by bronchoscopy. On 1 October diplopia occurred during right lateral gaze; on examination a slight adductive paresis of the left eye was noted. A CT scan revealed ventricular dilatation and a small dense lesion close to the fourth ventricle. A ventricular-pleural shunt was performed on 4 October. Left internuclear ophthalmoplegia and left peripheral facial weakness were noted on 11 November. In the days following, a bilateral horizontal gaze paralysis appeared, which was electrooculographically analysed on 27 November (see below). In mid-December, deglutition and phonation disorders, a left facial sensory loss, a mild right sensoro-motor deficit, a slight left sensoro-motor deficit and ocular bobbing were noted. Voluntary vertical eye movements, as well as abductive reflex movements of the right eye still existed on 20 December. The patient died from bronchopneumonia on 
21 December 1979. Post-mortem examination confirmed the existence of an epidermoid carcinoma of the left superior bronchus, and revealed metastases in the liver.

OCULOMOTOR EXAMINATION (27 NOVEMBER, 1979)

Eye movements were recorded separately for each eye using direct current electro-oculography. Horizontal recordings were approximately calibrated from the oculocephalic movement of the right eye, vertical recordings from voluntary saccades. At rest, both eyes were on the midline with no fixational instabilities.

Horizontal movements (fig 1) Voluntary saccades were absent for both eyes bilaterally, the eyes remaining fixed on the midline (fig 2a). Foveal pursuit movements (attempted with a small, smoothly-moving target) were also absent bilaterally (fig $2 \mathrm{~b}$ ), even when the target velocity was very slow $(5 \%$ s). Rightward full-field optokinetic stimulations (using alternating black and white stripes, moving at several velocities from $10 \%$ to $60 \%$ across a screen located $80 \mathrm{~cm}$ in front of the patient and covering $90^{\circ}$ of his visual field) elicited a slow movement of the right eye, up to $30^{\circ}$ rightwards, without any leftward quick phase (fig 2c); the velocity of this movement was slower than that of the stimulus, for example not exceeding $30 \% \mathrm{~s}$ when the stimulus velocity was $60 \%$; the right eye stayed in the eccentric position until the stimulus ceased and then it returned very slowly to the midline (at the rate of $10 \%$ ); the left eye remained on the midline. During leftward

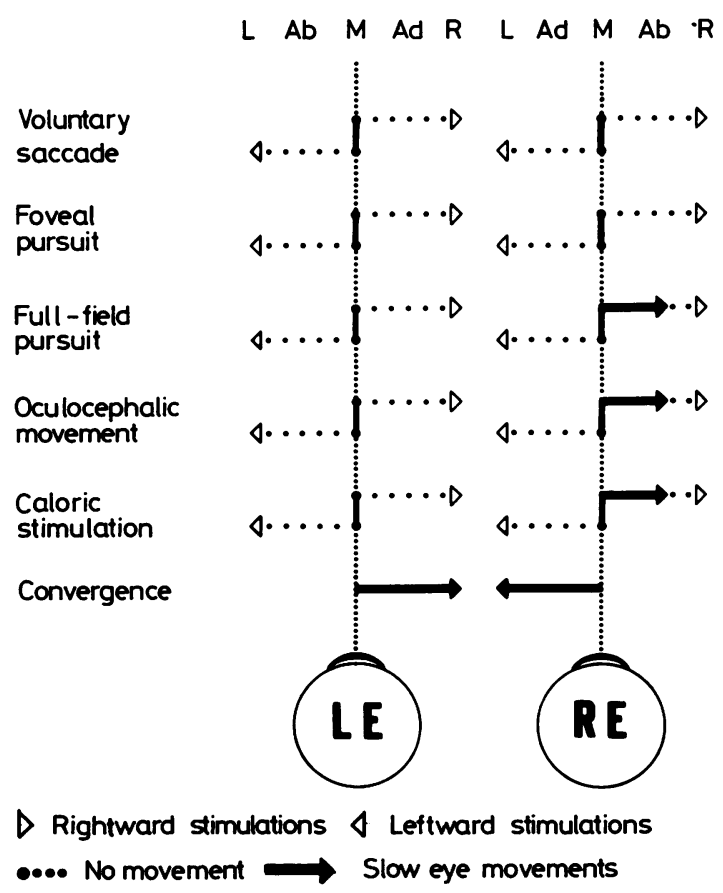

Fig 1 Horizontal eye movements. Ab: abduction; Ad: adduction; L: left; LE: left eye; $M$ : midline; $R$ : right; $R E$ : right eye.
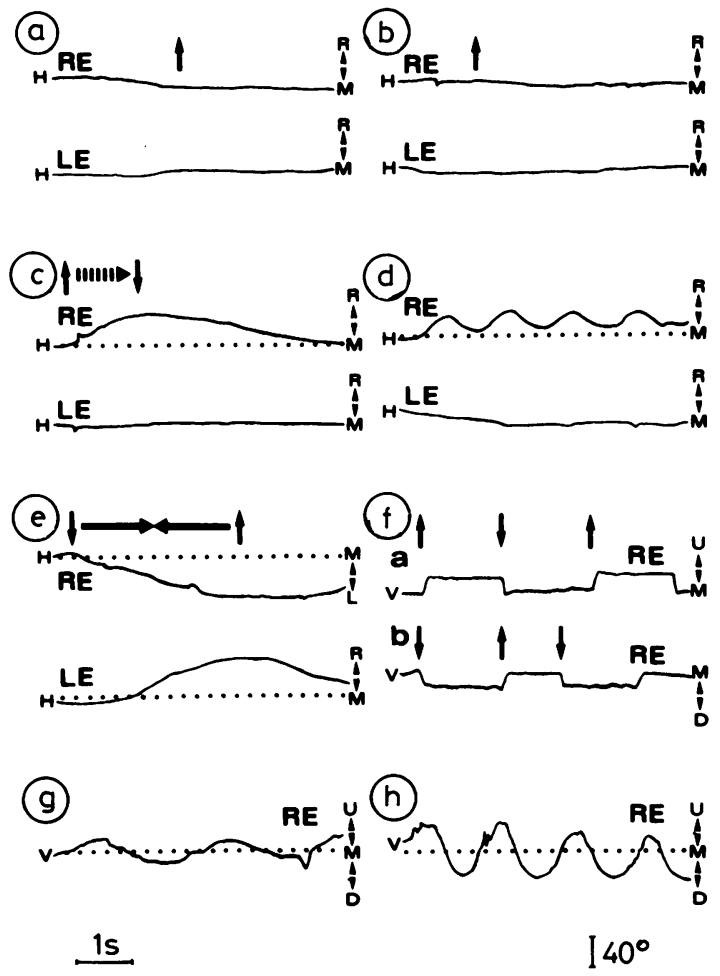

Fig 2 Electro-oculographic recordings. a, attempt (upward arrow) at voluntary rightward saccade: no movement. $b$, attempt (upward arrow) at rightward foveal pursuit: no movement. $c$, rightward full-field optokinetic stimulation (between both vertical arrows) with a velocity of $60 \%$ : rightward slow movement of the right eye only, up to about $30^{\circ}$ laterally, with a maximum velocity of $30 \%$; very slow passive return to the midline afterwards $(10 \% \mathrm{~s}) . \mathrm{d}$, horizontal oculocephalic movements: right eye only moved from midline to about $30^{\circ}$ rightwards. e, convergence (between both vertical arrows): normal for both eyes. $f$, vertical saccades (right eye only). a, upward saccades (upward arrows) and return to midline (downward arrow): normal velocities. $b$, downward saccades (downward arrows) and return to the midline (upward arrow): velocities at times slightly slowed. $g$, vertical foveal pursuit: partially saccadic. $h$, vertical oculocephalic movement: normal. $D=$ down; $H$ : horizontal recording; $L=$ left; $L E=$ left eye; $M$ $=$ midline; $R=$ right $R E=$ right eye; $U=u p ; V=$ vertical recording.

full-field optokinetic stimulations neither eye moved: there was no slow or quick phase. Oculocephalic manoeuvre (passive rotation of the head performed by the examiner's hands) allowed only the right eye to move up to $30^{\circ}$ rightwards, and to return to the midline (which was not crossed to the left), the left eye remaining fixed (fig 2d). This oculocephalic movement was observed only with rapid displacements of the head: the highest peak velocity of eye movements was then about $100 \%$ in the rightward move- 
ment as well as in the return to the midline. Caloric stimulation of the right ear with cold water induced a tonic deviation of the right eye, up to $30^{\circ}$ rightwards, lasting a few minutes without any leftward quick phase, or any movement of the left eye. After caloric stimulation of the left ear, both eyes remained fixed to the midline. Convergence was normal for both eyes (fig 2e).

Vertical movements Voluntary saccades were normal in both directions (fig 2f), for amplitude as well as velocity in most of the movements $\left(200 \%\right.$ in a $30^{\circ}$ movement for example). At times, however, velocities of certain saccades were slightly slowed (up to $150^{\circ} / \mathrm{s}$ in a $30^{\circ}$ movement). Sustained upward and downward fixations were possible, without any nystagmus. Foveal pursuit was slightly saccadic in both directions (fig $2 \mathrm{~g}$ ). Oculocephalic movements were normal both upwards and downwards (fig $2 \mathrm{~h}$ ). Vertical optokinetic and bilateral caloric stimulations were not performed.

\section{NEUROPATHOLOGICAL OBSERVATIONS}

Macroscopic examination The brain was slightly swollen. Evidence of the operation was visible in the upper part of the left frontal lobe. A tumour was found on the surface of the left temporal pole. The brainstem and cerebellum were separated from the hemispheres at the pontine level. A small tumoral nodule was observed in the pontine tegmentum, more extensive on the left than the right side. Sections of hemisphere were taken in the coronal plane. The basal ganglia region and the posterior fossa structures were divided into two blocks and cut serially from the pontine section.

Histology The fragments were embedded in celloidin and stained by haematoxylin-eosin, Nissl, and Wolcke. The main finding was the presence of three metastases, which included carcinoma cells, pseudo-acinus cavities, epidermoid zones, nuclear malformations, atypical mitoses, necrotic areas, and mild vascular proliferation. These tumours were surrounded by oedema and perivascular cuffings.

The largest tumour was located mainly in the left pontine tegmentum. It almost completely spared the medulla in which the vestibular nuclei were undamaged on both sides. It extended from the superior tip of the medulla (at the upper pole of the olives) up to the locus coeruleus level in the upper pons. Its diameter was largest at mid-pons. The fourth ventricle was dilated and largely filled by the tumour which had also almost completely destroyed the left pontine tegmentum. In the lower pons (fig 3), the left medial longitudinal fasciculus (MLF), the left abducens and facial nerve nuclei and the neighbouring left pontine reticular formation (including the caudal paramedian part) no longer existed. The fibres of the left sixth and seventh cranial nerves were demyelinated at their exits from the brainstem. Furthermore, the right pontine tegmentum had been shifted rightwards. Despite a significant displacement of the medial and right lateral sulci most of the structures enclosed in this right tegmentum were not directly damaged and were still visible (figs 4 and 5): in particular the right MLF, the right abducens nucleus and the nucleus of the right facial nerve and its genu. The fibres of the right sixth and seventh nerves were normal at their brainstem exits. On the other hand, the region related to the right caudal paramedian pontine reticular formation, located ventrally to the right abducens nucleus, was much damaged and swollen. At mid-pons level (fig 6), the tumour was more extensive and involved the tegmentum almost totally, with a slight predominance on the left side. Ventrally, it reached the dorsal part of the medial lemnisci. Neither MLF was visible and the area of the rostral paramedian pontine reticular formation (situated ventrally to the MLF) was completely destroyed on both sides. In the upper pons only a few cells of the left locus coeruleus were still visible

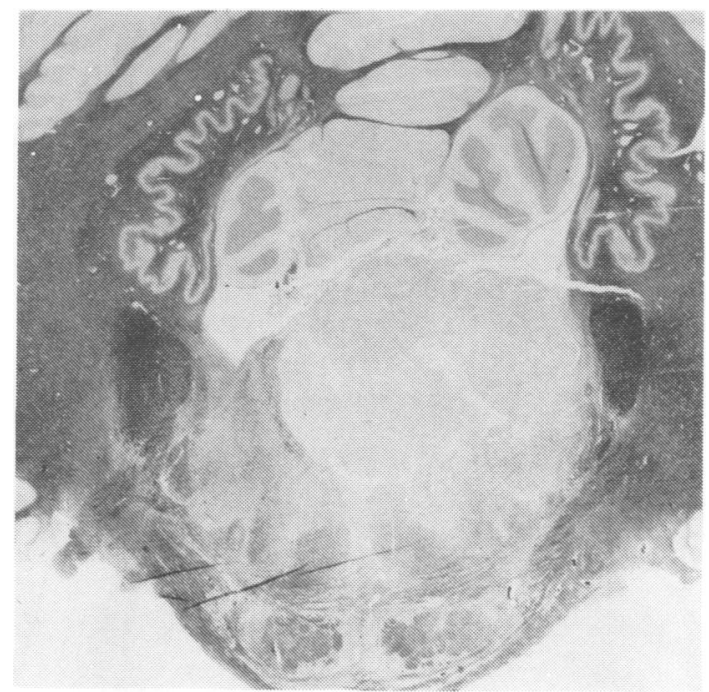

Fig 3 Lower pons. Wolcke stain. A tumour has developed within the tegmentum, mainly on the left side, laterally shifting the right side, and largely filling the fourth ventricle. $(\times 2)$

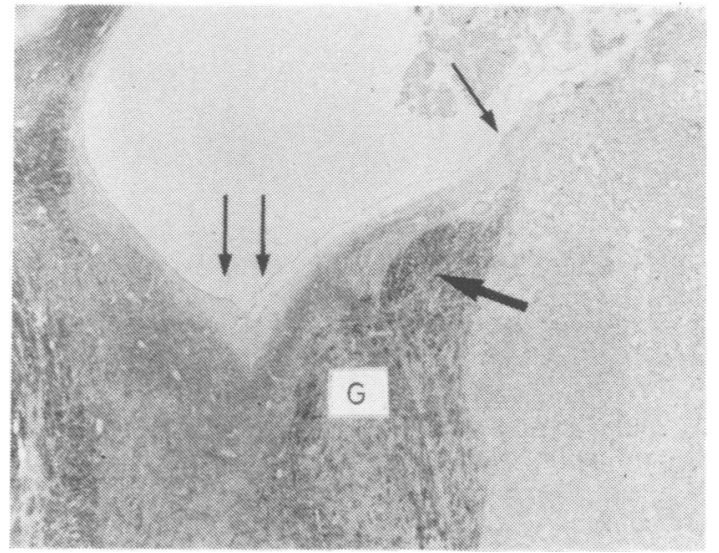

Fig 4 Lower pons. Wolcke stain. The medial (one arrow) and lateral (two arrows) sulci of the fourth ventricle are displaced towards the right side. The right MLF (thick arrow) and facial nerve genu $(G)$ are pushed laterally but not involved in the tumoral process (pale). $(\times 12)$ 


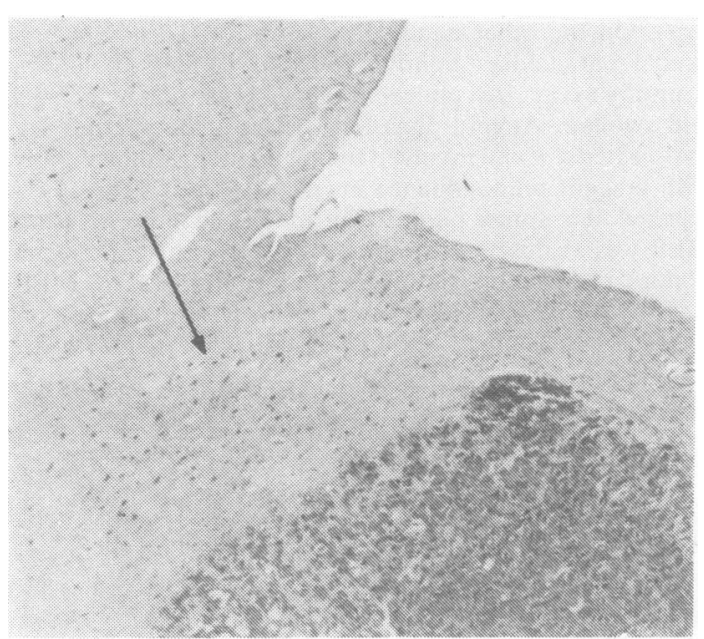

Fig 5 Lower pons. Nissl stain. The right abducens nucleus (arrow) is displaced but not destroyed by the tumour (dark). $(\times 18)$

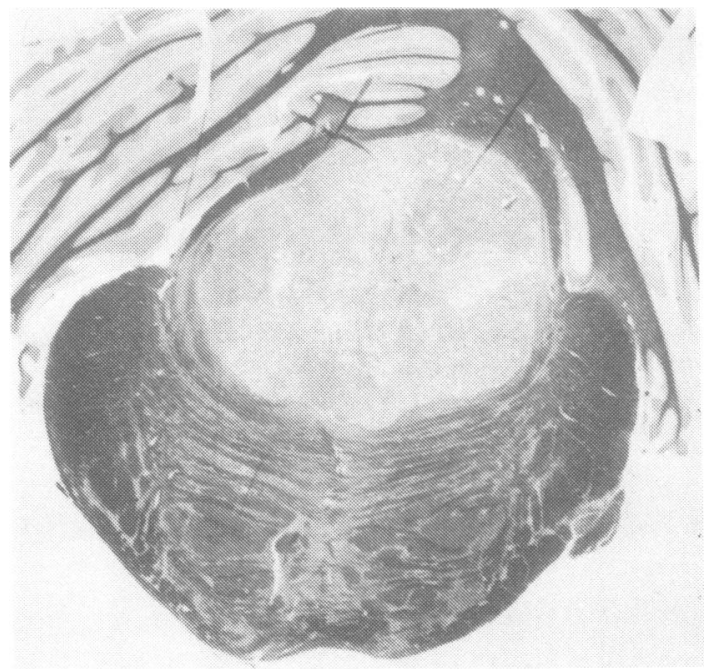

Fig 6 Mid-pons. Wolcke stain. The tumour has filled the fourth ventricle and has developed within the tegmentum, coming into contact with both medial lemisci. The paramedian pontine reticular formation area is completely destroyed on both sides. $(\times 2)$

near the superior part of the tumour. At the midbrain level, the left MLF was demyelinated but not the right one. There was a slight pallor of the left pyramidal tract in all the brainstem sections.

A second metastatic nodule was found in the left temporal pole, $1 \mathrm{~cm}$ in diameter at its largest. In the right amygdala nucleus a third small metastasis, not exceeding 2 $\mathrm{mm}$, was discovered. A diffuse vascular dilatation, an arachnoid thickening, and polynuclear thrombi in the lumen of small vessels were also noted.

\section{Discussion}

The location of this metastatic tumour, which involved the pontine tegmentum almost totally on the left side but also partly on the right, accounts for the impairment of lateral eye movements and the preservation of vertical movements. However, certain clear dissociations in these oculomotor disorders deserve comment.

Horizontal movements Since the left abducens nucleus had been destroyed, and with it both the motoneurons mediating the left eye abduction and the internuclear neurons controlling the right eye adduction, neither eye could move to the left. Likewise, the destruction of the left MLF explains the loss of the left eye adduction. Only convergence allowed both eyes to go inwards. These oculomotor palsies illustrate a "one-and-a-half" syndrome. ${ }^{67}$ However, this syndrome was extended since the right eye abduction was also defective, completely for saccades and foveal pursuit, partially for the other eye movements in which amplitude was reduced.

The loss of all rightward saccades in the right eye implies damage to the right paramedian pontine reticular formation. This formation is located in man, as in the monkey, very close to the midline, ventrally but also rostrally to the abducens nucleus. ${ }^{8-10}$ Consequently, in this case it was destroyed by the tumour, totally in its rostral portion (at midpons level) and largely in its caudal portion (near the abducens nucleus). Indeed, a small part of the right caudal paramedian pontine reticular formation (lying laterally) was spared by the tumour itself, but being located in its immediate vicinity was probably impaired functionally by the oedema and the peritumoral compression.

The absence of rightward, right eye, foveal pursuit may be variously explained. If a final necessary relay for foveal pursuit exists in the tonic cells of the paramedian pontine reticular formation, ${ }^{112}$ these cells must have been damaged by the lesion, as was the case for the phasic cells which control saccades. Even admitting now that such a paramedian pontine reticular formation relay is doubtful in view of other more recent preliminary data reported in the mon$k e y,{ }^{13}$ the final tegmental part of the supranuclear pathways involved in horizontal smooth pursuit was almost certainly damaged by the lesion at the midpons level.

The conservation of a rightward full-field pursuit in the right eye (along with other similarly directed eye movements originating in the vestibular system) allowed one to assume prior to post-mortem study that the right abducens nucleus and fibres as well as 
the left vestibular nuclei had not been destroyed. It is likely that the compression of the right pontine tegmentum caused a partial functional impairment in its enclosed oculomotor structures, particularly of the abducens motoneurons, thus explaining how the amplitude of all remaining rightward movements could be reduced equally. One of the most surprising clinical features was to find a rightward full-field pursuit among these movements since arguments are not lacking to account for loss of foveal pursuit in this direction. Such a dissociation of these two types of pursuit in a brainstem lesion is, to our knowledge, unique. It appears to confirm current thinking in which foveal pursuit pathways and those of optokinetic or full-field pursuit are considered to be separate in the premotor areas. The former would no directly involve the vestibular nuclei ${ }^{14}$ but would implicate partly the cerebellum,,$^{15-18}$ and especially certain zones of the brainstem possibly including the nucleus reticularis tegmenti pontis, ${ }^{19}$ located just dorsally to the medial lemnisci in mid-pons and consequently destroyed in our case. The latter, involving also partly the cerebellum ${ }^{18}$ and possibly the medial pontine nuclei ${ }^{20}$ (located ventral to the medial lemnisci and consequently undamaged in our case), would afterwards principally pass through the vestibular nuclei ${ }^{14}{ }^{21}$ from which they would join the abducens nuclei by direct tracts, as is the case with other reflex eye movements. Both the rightward full-field pursuit preservation and the loss of rightward foveal pursuit could thus be explained in this case. However, although it appears now unlikely, it may also be argued that the final part of the supranuclear pathways is identical for both types of pursuit, and only partially functional in our case. It would then be theoretically possible for a full-field visual stimulation to be simply more effective than a single foveal stimulation.

Vertical movements. The persistence of vertical oculocephalic movements suggested that, on one side at least, the MLF and the brachium conjonctivum had been spared. Recent clinical $^{22}$ and experimentals data have shown that the excitatory tracts mediating downward and upward reflex eye movements do indeed pass through these two types of structures. Our anatomical study demonstrated right MLF presence at the lower pons level; it was not found in the mid-pons but there was no demyelination at the mid-brain level, compared to the left MLF. Owing to the fact that the EOG examination was performed more than 3 weeks before death it is reasonable to postulate that such involvement of the right MLF occurred after this examination.

Normal vertical saccades, despite bilateral dam- age to the paramedian pontine reticular formation, is the last outstanding feature of this case. Saccades in all directions, including the vertical, are abolished after selective lesions of the caudal part of both paramedian pontine reticular formation in the awake monkey. ${ }^{132}$ This may be explained by the existence in the paramedian pontine reticular formation of phasic and pause cells, ${ }^{911} 13$ connected directly to the $\mathrm{MRF}^{24}$ and playing a critical role in vertical saccade triggering. Taking only the experimental findings into account, the paramedian pontine reticular formation could be considered as the last but one obligatory premotor relay in the genesis of voluntary vertical saccades, the MRF being the last. Data reported in man, however, do not seem to confirm these experimental results as yet. Indeed, although voluntary vertical movements may be suppressed transiently ${ }^{25}$ or slowed ${ }^{26}$ in certain cases of bilateral lesions in the lower pontine tegmentum (not of course involving the slightest coma), the deficit of these movements is neither long lasting nor severe. Furthermore, in some other cases with large lesions bilaterally damaging the paramedian pontine reticular formation area, in its rostral portion (ref 27 , case 1 ; ref 28 , case 6 ) as well as in its caudal portion (ref 29 , case 1 ; ref 30 , case 1 ), voluntary vertical movements appeared normal, as in our case. In this last, the normality of vertical saccades could theoretically result from the preservation of a small portion of the right caudal paramedian pontine reticular formation. However, this portion could in our opinion be functionally impaired (see above in discussion). Accordingly, it may be finally asked whether the premotor organisation of voluntary vertical saccades is not far more independent of paramedian pontine reticular formation influences in man than in the monkey.

\section{References}

${ }^{1}$ Henn V, Hepp K, Büttner-Ennever JA. The primate oculomotor system. II pre-motor system. A synthesis of anatomical, physiological and clinical data. Human Neurobiol 1982;I:87-95.

${ }^{2}$ Pierrot-Deseilligny C, Chain F, Lhermitte F. Syndrome de la formation réticulaire pontique. Précisions physiopathologiques sur les anomalies des mouvements oculaires volontaires. Rev Neurol (Paris) 1982;138:517-32.

${ }^{3}$ Büttner-Ennever JA, Büttner U, Cohen B, Baumgartner G. Vertical gaze paralysis and the rostral interstitial nucleus of the medial longitudinal fasciculus. Brain 1982;105:125-49.

${ }^{4}$ Pierrot-Deseilligny C, Chain F, Gray F, Serdaru M, Escourolle R, Lhermitte F. Parinaud's syndrome. Electro-oculographic and anatomical analyses of six vascular cases with deductions about vertical gaze 
organization in the premotor structures. Brain 1982;105:667-96.

${ }^{5}$ Highstein SM, Reisine H. Synaptic and functional organization of vestibulo-ocular reflex pathways. In: Granit R, Pompeiano O, eds. Reflex Control of Posture and Movement. Amsterdam: Elsevier, 1979:431-42.

${ }^{6}$ Fisher CM. Some neuro-ophthalmological observations. J Neurol Neurosurg Psychiatry 1967;30:383-92.

${ }^{7}$ Pierrot-Deseilligny C, Chain F, Serdaru M, Gray F, Lhermitte F. The "one-and-a-half" syndrome. Electro-oculographic analyses of five cases with deductions about the physiological mechanisms of lateral gaze. Brain 1981;104:665-99.

${ }^{8}$ Cohen B, Komatsuzaki A, Bender MB. Electrooculographic syndrome in monkeys after pontine reticular formation lesions. Arch Neurol 1968;18: 78-92.

${ }^{9}$ Henn V, Cohen B. Coding of information about rapid eye movements in the pontine reticular formation of alert monkeys. Brain Res 1976;108:307-25.

${ }^{10}$ Pierrot-Deseilligny C, Chain F, Gray F, Escourolle R, Castaigne P. Paralysies supranucléaires de la latéralité d'origine protubérantielle. A propos de deux observations anatomo-cliniques avec enregistrements électro-oculographiques et électromyographiques. Rev Neurol (Paris) 1979;135:741-62.

${ }^{11}$ Keller EL. Participation of medial pontine reticular formation in eye movement generation in monkey. $J$ Neurophysiol 1974;37:316-32.

${ }^{12}$ Lestienne F, Whittington DA, Bizzi E. Single cell recording from the pontine reticular formation in monkey. Behavior of preoculomotor neurons during eye-head coordination. In: Fuchs AF, Becker W, eds. Progress in Oculomotor Research. Amsterdam: Elsevier, 1981:325-33.

${ }^{13}$ Lang W, Henn V, Hepp K. Gaze palsies after selective pontine lesions in monkeys. In: Roucoux A, Crommelinck M, eds. Physiological and Pathological Aspects of Eye Movements. The Hague: Junk, 1982:209-18.

${ }^{14}$ Büttner U, Waespe W, Henn V. The role of the cerebellum and the vestibular system in the generation of slow conjugate eye movements. In: Huber A, Klein D, eds. Neurogenetics and Neuro-Opthalmology. Amsterdam: Elsevier, 1981:89-102.

15 Westheimer G, Blair SM. Functional organization of primate oculomotor system revealed by cerebellectomy. Exp Brain Res 1974;21:463-72.

${ }^{16}$ Avanzini G, Girotti F, Crenna P, Negri S. Alterations of ocular motility in cerebellar pathology. Arch Neurol
1979;36:274-80.

${ }^{17}$ Larmande P, Delplace MP, Autret A. Influence du cervelet sur la statique oculaire et les mouvements de poursuite visuelle. Rev Neurol (Paris) 1980;136: 327-39.

${ }^{18}$ Zee DS, Yamazaki A, Butler PH, Gücer G. Effects of ablation of flocculus and paraflocculus on eye movements in primate. $J$ Neurophysiol 1981;46:878-99.

${ }^{19}$ Keller EL, Crandall WF. Neural activity in the nucleus reticularis tegmenti pontis in the monkey related to eye movements and visual stimulation. In: Cohen B, ed. Vestibular and Oculomotor physiology. New York: The New York Academy of Sciences 1981:249-61.

${ }^{20}$ Keller EL, Crandall WF. Neural responses to optokinetic stimuli in pontine nuclei of behaving monkey. $J$ Neurophysiol 1983;49:169-87.

${ }^{21}$ Azzena GB, Azzena MT, Marini R. Optokinetic nystagmus and the vestibular nuclei. Exp Neurol 1974;42:158-68.

22 Jenkin LR, Margolis G, Reeves AG. Reflex vertical gaze and the medial longitudinal fasciculus. J Neurol Neurosurg Psychiatry 1978;41:1084-91.

${ }^{23}$ Bender MB, Shanzer S. Oculomotor pathways defined by electric stimulation and lesions in the brain stem of monkeys. In: Bender MB, ed. The Oculomotor System. New York: Harper, 1964:81-140.

${ }^{24}$ Büttner-Ennever JA, Büttner U. A cell group associated with vertical eye movements in the rostral mesencephalic reticular formation in the monkey. Brain Res 1978;151:31-47.

${ }^{25}$ Hoyt WF, Daroff RB. Supranuclear disorders of ocular control system in man. In: Bach-Y-Rita P, Collins C, Hyde J, eds. The Control of Eye Movements. New York: Academic Press, 1971:175-235.

${ }^{26}$ Larmande P, Henin D, Jan M, Elie A, Gouazé A. Abnormal vertical eye movements in the locked-in syndrome. Ann Neurol 1982;11:100-2.

${ }^{27}$ Halsey JH, Ceballos R, Crosby EC. The supranuclear control of voluntary lateral gaze. Neurology (Minneap) 1967;17:928-33.

${ }^{28}$ Hawkes CH. "Locked-in Syndrome". A report of seven cases. Br Med J 1974;4:379-82.

${ }^{29}$ Nordgren RE, Markesbery WR, Fukuda K, Reeves AG. Seven cases of cerebro-medullospinal disconnection. The "Locked-in Syndrome". Neurology (Minneap) 1971;21:1140-8.

${ }^{30}$ Cambier J, Henin D, Escourolle R, Masson M, Dehen H, Lagarde P. Signe du "Bobbing" oculaire. Etude anatomo-clinque de deux cas. Rev Neurol (Paris) 1974;130:433-44. 